\title{
Contribuição da prática do canto coral para a formação interprofissional na área de saúde
}

Rodrigo Andrade Teixeira, Francisco José Passos Soares, Mércia Lamenha Medeiros, Lenilda Austrilino

\section{Resumo}

O objetivo deste trabalho é relatar uma pesquisa que está sendo realizada no Mestrado Profissional Ensino na Saúde. Consta de reflexões sobre a implantação da educação interprofissional, tendo como ponto de partida o coral da instituição e sua contribuição para o desenvolvimento de habilidades e competências para a prática colaborativa em saúde. A indissociabilidade ensino, pesquisa e extensão, princípio que direciona o projeto pedagógico para os cursos das instituições públicas de ensino superior, aponta para a necessidade de utilizar espaços extencionistas como estratégia favorável ao processo ensino aprendizagem. Assim, o Coral Extencionista da UNCISAL, constitui locus de desenvolvimento para a iniciação em Educação Interprofissional pela potencialidade em estimular o aprimoramento de práticas colaborativas. O Coral é composto por discentes da graduação dos cursos de medicina, enfermagem, fisioterapia, terapia ocupacional, fonoaudiologia e profissionais de diversas áreas, além da saúde. Sendo um grupo de aprendizagem musical, desenvolvimento vocal, de integração e inclusão social, constituído por diferentes relações interpessoais e de ensino-aprendizagem, exige a aquisição de competências colaborativas, uma vez que cada grupo de voz deve aprender sobre o trabalho conjunto e sobre as especificidades de cada um. Considerando que o canto coral proporciona trabalho em equipe, integração, respeito à especificidade, favorece ao planejamento participativo, a tolerância, a negociação e a tomada de decisão, inserir a prática do canto coral, como um programa de iniciação a educação interprofissional, poderá consubstanciar o desenvolvimento de competências colaborativas, a ação de cada um levará aos resultados esperados por todos. Visando verificar se a participação no coral desenvolve habilidades e competências necessárias a prática colaborativa e a educação interprofissional será realizada entrevistas com os discentes, dos vários cursos da área da saúde que integram o coral, na perspectiva de encontrar congruências em relação ao trabalho em equipe e a colaboração entre eles, durante o desenvolvimento das atividades.

Descritores: Educação interprofissional, Graduação em saúde, Prática colaborativa 